Diabetologia 10,679--684 (1974)

(C) by Springer-Verlag 1974

\title{
Control of Insulin Secretion in the Egyptian Sand Rat (Psammomys obesus)*
}

\author{
H. E. Lebovitz, S. White, E. Mikat and D.B. Hackel \\ Departments of Medicine, Physiology and Pathology, Duke University School of Medicine, Durham, N.C., USA
}

\begin{abstract}
Summary. Eighteen sand rats (Psammomys obesus) maintained on a vegetable or mixed vegetable and laboratory chow aiet were bled and their pancreases removed and incubated in vitro to study insulin release. Plasma glucose and insulin measurements showed that all the animals were either normal or had a mild non-ketotic diabetes mellitus-like syndrome. Pancreatic insulin content was high (13 to $20 \mathrm{U} / \mathrm{g}$ ) and insulin release in basal medium was 5 to 25 times that occurring with pancreas pieces from common laboratory animals. Basal in vitro insulin release correlated with the plasma insulin value
\end{abstract}

at the time of sacrifice. Glucose, tolbutamide and dibutyryl cyclic AMP did not significantly stimulate nor did dopamine inhibit insulin release from pancreases from normal or mildly diabetic sand rats. Glucagon, however, did significantly stimulate in vitro insulin release. Insulin secretion in the sand rat has unique control mechanisms.

Key words: Spontaneous diabetes, sand rat, Psammomys obesus, plasma insulin, pancreatic insulin content, in vitro insulin secretion, glucose, tolbutamide, glucagon, dopamine, dibutyryl cyclic AMP.

\section{Introduction}

Diabetes mellitus-like syndromes in experimental animals provide unique opportunities to investigate many of the factors which may be involved in the etiology and pathogenesis of the human disease. The Egyptian sand rat is such a model. In his native habitat, the sand rat ingests foods which have low calorie and high mineral content [1]. In this marginal milieu the sand rat has normal blood glucose (less than $80 \mathrm{mg} / 100 \mathrm{ml}$ ) and normal tolerance to glucose [2]. However, when the animals are stressed (infection or capture) or when they consume a high caloric diet, such as that provided to ordinary laboratory animals, they develop a diabetes mellitus-like syndrome [3, 4]. This syndrome takes the form of an acute fulminating illness, characterized by ketosis, acidosis and rapid death, or a more chronic illness, characterized by obesity and hyperinsulinemia with or without hyperglycemia [3, 4]. This latter form of the syndrome is considered a parallel to the maturity onset form of human diabetes mellitus.

Studies concerned with insulin secretion and action in the sand rat show that the acute fulminating ketotic form of the disease is associated with insulin deficiency while the chronic non-ketotic form is associated with marked elevation of plasma insulin levels and apparent peripheral tissue resistance to insulin action [3-6]. In vivo studies of plasma insulin responses in the non-ketotic form of the syndrome indicate that increased insulin secretion is the earliest and most dramatic change noted [7]. This increased plasma insulin bears a striking relationship to increased caloric

* These studies were supported by grants from the National Institute of Arthritis, Metabolic and Digestive Diseases (AM 08949 and AM 01324); and were carried out during the tenure of Research Career Development Award K 3 AM 17,954 to Dr. Lebovitz and Research Career Award HL-K6-14188 to Dr. Hackel. intake [7], but is only slightly or not at all affected by the ingestion of specific nutrients. Glucose ingestion, for example, causes little if any rise in plasma insulin [2].

The present study reports the results of in vitro studies undertaken to investigate the control of insulin secretion in the sand rat. The data show that: 1) the pancreas of the sand rat secretes remarkably more insulin in vitro than that of most other species; 2) insulin secretion from the sand rat pancreas in vitro is not stimulated by glucose or tolbutamide and is not inhibited by dopamine; and, 3) glucagon markedly stimulates insulin secretion from sand rat pancreas.

\section{Materials and Methods}

\section{Sand Rats}

The characteristics of the 18 sand rats used in this study are listed in Table 1. All of the sand rats were obtained from our breeding colony at Duke. The age of the animals varied from 8 to 32 months. Fourteen were male and four female. The dietary intake of the animals varied, but most had been on a vegetable or mixed vegetable and laboratory chow diet. The weights ranged from 118 to $225 \mathrm{~g}$.

\section{Incubation Technique}

The animals were brought to the laboratory several days before the experiments were to be done and were maintained on a vegetable diet. They were fed until the experiment began. They were anesthetized with ether and the pancreases removed, cleaned, cut into 15 to $25 \mathrm{mg}$ pieces, weighed and pre-incubated for $15 \mathrm{~min}$ in a Krebs-Ringer-Bicarbonate medium containing $5 \mathrm{mM}$ pyruvate, $5 \mathrm{mM}$ glutamate, $5 \mathrm{mM}$ fumarate, $3.3 \mathrm{mM}$ glucose and $400 \mathrm{mg} / 100 \mathrm{ml}$ bovine 
serum albumin, equilibrated with $95 \% \quad \mathrm{O}_{2}-5 \% \quad \mathrm{CO}_{2}$ (modified KRB medium). The pieces were then incubated in fresh modified KRB medium for $15 \mathrm{~min}$ (Basal Incubation). Following this they were transferred to fresh modified KRB medium containing the treatment agent, and incubated for an additional 15 min (Treatment Incubation). All incubations were performed at $37^{\circ} \mathrm{C}$ in stoppered $10 \mathrm{ml}$ flasks in a gyrorotary shaker bath. At the end of the basal and treatment incubations, aliquots of the medium were placed in chilled tubes and directly assayed for insulin.
Insulin was measured directly by a radioimmunoassay technique.

\section{Glucagon Purification}

Glucagon with a low insulin content (Lot No. $258-234 \mathrm{~B} 167-1)$ was kindly given to us by Dr. Mary Root of the Eli Lilly Company. Before use in the in vitro incubations, the glucagon was chromatographed on a $2.5 \times 186 \mathrm{~cm}$ Sephadex G50 superfine column with $50 \%$ acetic acid as the eluent. ${ }^{125} \mathrm{I}$-insulin was added as a marker. Glucagon chromatographed as a single peak and was readily separated from the

Table 1. Characteristics of sand rat population studied

\begin{tabular}{|c|c|c|c|c|c|c|}
\hline $\begin{array}{l}\text { Animal } \\
\text { no. }\end{array}$ & $\begin{array}{l}\text { Age } \\
\text { (months) }\end{array}$ & Sex & $\begin{array}{l}\text { Weight } \\
\text { (g) }\end{array}$ & $\begin{array}{l}\text { Plasma } \\
\text { glucose } \\
(\mathrm{mg} / 100 \mathrm{ml})\end{array}$ & $\begin{array}{l}\text { Plasma } \\
\text { insulin } \\
(\mu \mathrm{U} / \mathrm{ml})\end{array}$ & $\begin{array}{l}\text { Basal in vitro } \\
\text { insulin release } \\
\text { ( } \mu \mathrm{U} / \mathrm{mg} / 15 \mathrm{~min})\end{array}$ \\
\hline 1 & 20 & $\mathrm{M}$ & 175 & 92 & $<2.5$ & $36.5 \pm 13.0$ \\
\hline 2 & 12 & $\mathrm{M}$ & 155 & 64 & 13 & $69.8 \pm 19.7$ \\
\hline 3 & 21 & $\mathrm{M}$ & 170 & 62 & 35 & $54.3 \pm 16.4$ \\
\hline 4 & 15 & $\mathrm{M}$ & 154 & 53 & 33 & $25.0 \pm 4.6$ \\
\hline 5 & 11 & $\mathrm{M}$ & 186 & 78 & 19 & $93.0+17.8$ \\
\hline 6 & 18 & $\mathrm{M}$ & 160 & 174 & 48 & $44.8 \pm 8.5$ \\
\hline 7 & 12 & $\mathrm{~F}$ & 170 & 71 & 42 & $120.7 \pm 36.3$ \\
\hline 8 & 14 & $\mathrm{M}$ & 225 & 96 & 89 & $86.4+31.9$ \\
\hline 9 & 32 & $\mathrm{M}$ & 220 & 98 & 104 & $147.6 \pm 45.6$ \\
\hline 10 & 16 & $\mathrm{M}$ & 190 & 66 & 117 & $54.6 \pm 16.4$ \\
\hline 11 & 15 & $\mathrm{M}$ & 180 & 87 & 126 & $46.3 \pm 17.4$ \\
\hline 12 & 13 & $\mathrm{M}$ & 155 & 62 & 162 & $48.6 \pm 14.5$ \\
\hline 13 & 13 & $\mathrm{~F}$ & 118 & 97 & 187 & $74.3 \pm 21.8$ \\
\hline 14 & 15 & $\mathrm{~F}$ & 140 & 68 & 262 & $54.3 \pm 13.8$ \\
\hline 15 & 16 & $\mathbf{M}$ & 200 & 82 & 495 & $126.5 \pm 26.2$ \\
\hline 16 & 8 & $\mathbf{M}$ & 195 & 98 & 222 & $96.0 \pm 22.0$ \\
\hline 17 & $10 \% / 2$ & $\mathrm{~F}$ & 220 & 168 & 445 & $246.1 \pm 51.2$ \\
\hline 18 & 18 & M & 215 & 125 & 204 & $172.4 \pm 62.8$ \\
\hline
\end{tabular}

a Data are mean \pm S.E.

Table 2. Insulin content and insulin release from sand rat pancreatic pieces

\begin{tabular}{rllll}
\hline Animal & $\begin{array}{l}\text { Plasma } \\
\text { glucose } \\
(\mathrm{mg} / 100 \mathrm{ml})\end{array}$ & $\begin{array}{l}\text { Plasma } \\
\text { insulin } \\
(\mu \mathrm{U} / \mathrm{ml})\end{array}$ & $\begin{array}{l}\text { Insulin content } \\
\text { of pancreas pieces } \\
(\mathrm{mU} / \mathrm{mg})\end{array}$ & $\begin{array}{l}\text { \% of content released } \\
\text { in basal incubation }\end{array}$ \\
\hline 6 & 174 & 48 & $13.17 \pm 6.42(8)$ & $0.28 \pm 0.13(8)$ \\
18 & 125 & 204 & $20.49 \pm 6.92(10)$ & $0.63 \pm 0.42(10)$ \\
16 & 98 & 222 & $19.13 \pm 9.19(9)$ & $0.52 \pm 0.55(9)$ \\
15 & 82 & 495 & $13.07 \pm 7.31(10)$ & $1.04 \pm 0.58(10)$ \\
\hline
\end{tabular}

a Data are the mean $\pm S . D$. of the number of measurements in parenthesis

Insulin release in the basal incubation is expressed as $\mu \mathrm{U}$ of insulin released per $\mathrm{mg}$ of pancreas per $15 \mathrm{~min}$ of incubation. Insulin release in the treatment incubation is expressed as the ratio relative to the release in the basal incubation.

\section{Pancreatic Insulin Content}

Following completion of the treatment incubation, each pancreatic piece was immediately homogenized and extracted in $4 \mathrm{ml}$ of acid ethanol by the method of Scott and Fisher [8]. The supernatants were diluted $1: 1000$ with a $0.1 \mathrm{M}$, $\mathrm{pH} 7.0$ sodium phosphate buffer which contained $200 \mathrm{mg} / 100 \mathrm{ml}$ bovine serum albumin. contaminating insulin. Following lyophilization the glucagon was reconstituted as a $1 \mathrm{mg} / \mathrm{ml}$ solution and aliquots frozen until used. The purified glucagon contained $10 \mu \mathrm{U}$ insulin per $50 \mu \mathrm{g}$ of glucagon, as compared to the starting material which contained $345 \mu \mathrm{U}$ per $50 \mu \mathrm{g}$ of glucagon.

\section{Analytical Methods and Chemicals}

Insulin was measured by a double antibody radioimmunoassay technique [9]. Insulin concentrations were calculated using a sand rat insulin standard that had been bioassayed. The sand rat insulin standard displaced the pork ${ }^{125} \mathrm{I}$-insulin tracer 
from the anti-pork insulin antibody with $50 \%$ the activity of pork insulin. In all assays a pork standard was run simultaneously. Plasma glucose was determined on barium hydroxide-zinc sulfate filtrates by a glucose oxidase method [10]. Student's t test was used to determine the significance of differences between means [11].

$\mathrm{N}^{6}, \mathrm{O}^{2}$-dibutyryl eyclic adenosine $3^{\prime} 5^{\prime}$ monophosphate (DB-AMP), and 3-hydroxytyramine hydrochloride (dopamine) were purchased from Calbiochem (Los Angeles, California). Tolbutamide was a gift of the Upjohn Company (Kalamazoo, Michigan).

\section{Results}

\section{Metabolic Status of Sand Rat Population}

Table 1 gives the results of the plasma glucose and insulin levels of each animal just prior to sacrifice. From our previous studies we define a normal resting plasma glucose for the sand rat as $<80 \mathrm{mg} / 100 \mathrm{ml}$, and a definitely elevated value as $>100 \mathrm{mg} / 100 \mathrm{ml}$. Only 3 of the 18 sand rats had a plasma glucose in the clearly elevated range (animals 6, 17 and 18). The plasma insulin in nondiabetic, unstressed sand rats is $<40 \mu \mathrm{U} / \mathrm{ml}$. Five sand rats in the present study

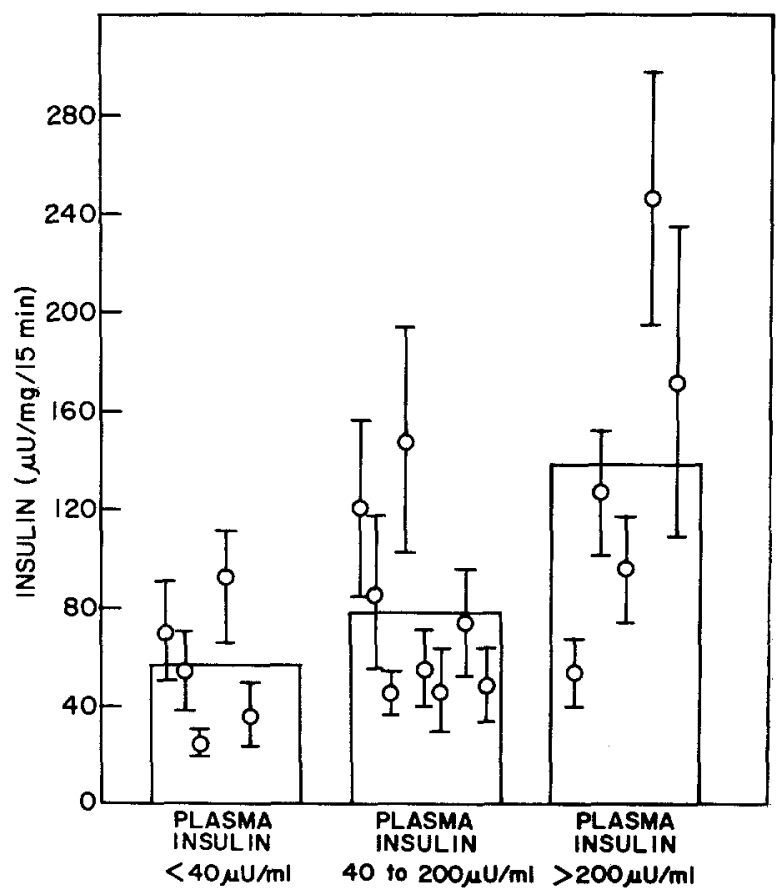

Fig. 1. Relationship between plasma insulin level of sand rats prior to sacrifice and subsequent in vitro basal insulin release from the animals' pancreatic pieces. Each point is the mean and the brackets the S.E. of basal insulin secretion from pancreas pieces from each individual sand rat (these data are plotted on the ordinate). The sand rats have been subdivided into three groups on the basis of their plasma insulin levels (Abscissa). The bar is the mean insulin release for each group had plasma insulins $<40 \mu \mathrm{U} / \mathrm{ml} ; 8$ had values from 41 to $200 \mu \mathrm{U} / \mathrm{ml}$ and 5 had values $>200 \mu \mathrm{U} / \mathrm{ml}$.

\section{Pancreatic Insulin Content}

The insulin content of the pancreatic pieces following the in vitro incubation was measured in 4 animals. Table 2 shows that the mean insulin content was between 13 and $20.5 \mathrm{U} / \mathrm{g}$. In each individual sand $\mathrm{rat}^{\prime} \mathrm{s}$ pancreas there was a marked difference in insulin content for each piece, as shown by the very large standard deviations. This variation is much greater than that which occurs in other animal species, such as the mouse, rabbit or golden hamster. In these same experiments, the insulin released by each piece when incubated in vitro, under basal conditions (modified KRB buffer) was also determined (Table 1). From these data and the insulin content, the percent of pancreatic insulin released during basal conditions was calculated for these 4 animals, and varied from 0.28 to $1.04 \%$. While there seemed to be no good correlation between the plasma insulin prior to sacrifice and the pancreatic insulin content, there did appear to be a good correlation between the percent of stored insulin released under basal conditions and the plasma insulin level.

Since pancreatic pieces from the same animal have this marked variability in both pancreatic insulin content and basal insulin release, each pancreas piece must serve as its own control if the effects of stimulatory or inhibitory agents on insulin secretion are to be studied.

\section{Basal Insulin Release}

Table 1 lists the basal in vitro insulin release of pancreatic pieces for each animal. The mean basal insulin release for individual animals varies from 25.0 to $246.1 \mu U$ per $\mathrm{mg}$ per $15 \mathrm{~min}$. Fig. 1 groups the sand rats into those animals with normal, moderately elevated and markedly elevated plasma insulin and shows that the basal release of insulin from an animal's pancreatic pieces in vitro is correlated with the plasma insulin level of the animal prior to sacrifice.

\section{Stimulated Insulin Release}

The amounts of insulin released in vitro from pancreatic pieces by agents which are known to stimulate insulin release in other animal species are shown in Table 3 . The data are grouped according to the plasma insulin levels at the time of sacrifice. All of the data are expressed as the ratio of insulin release by the pieces during the treatment incubation, as compared to that during the basal incubation for the same pieces. For each animal the results for all pieces (3 or 4 ) were averaged. The mean value for the group is that obtained using the average for each animal as a single value. Control refers to pieces that are incubated under basal conditions during the treatment as well as the basal incubation period. Apparently 
in vivo plasma insulin levels have no significant effect on the amount of insulin released in vitro in response to either glucose or tolbutamide.

Since the $\beta$-cell secretory state of this group of sand rats prior to sacrifice had no effect on in vitro insulin secretion in response to stimuli, the data from all the animals were pooled to determine the effect of various treatments on insulin secretion. Fig. 2 presents the data for all the animals combined. Neither glucose, tolbutamide nor dibutyryl cyclic AMP stimulated in vitro insulin release. Dopamine did not significantly alter insulin secretion. Glucagon, however, markedly stimulated insulin release from pieces of sand rat pancreas.

Table 3. In vitro pancreatic insulin release: Effect of plasma insulin levels in vivo

\begin{tabular}{|c|c|c|c|}
\hline \multirow{2}{*}{$\begin{array}{l}\text { Plasma insulin } \\
(\mu \mathrm{U} / \mathrm{ml})\end{array}$} & \multicolumn{3}{|c|}{ In vitro insulin release ( $\%$ of basal secretion) $)^{a}$} \\
\hline & Control & Glucose $(3 \mathrm{mg} / \mathrm{ml})$ & Tolbutamide $(1 \mathrm{mg} / \mathrm{ml})$ \\
\hline$<40$ & $1.03+0.15(5)$ & $1.17 \quad(1)$ & $1.53 \pm 0.55(3)$ \\
\hline $40-100$ & $1.14 \pm 0.32(3)$ & $1.52 \pm 0.28(2)$ & $1.25 \pm 0.11$ \\
\hline $101-200$ & $1.41+0.27$ & $1.74+0.73(4)$ & 0.85 \\
\hline$>200$ & $1.47 \pm 0.42(4)$ & $1.94 \pm 0.53(4)$ & $1.07 \pm 0.31(2)$ \\
\hline
\end{tabular}

a Data are the mean \pm S.E.

Table 4. In vitro insulin release from pieces of hamster, mouse and rabbit pancreas

\begin{tabular}{|c|c|c|c|c|c|}
\hline \multirow[t]{2}{*}{ Animal } & \multicolumn{2}{|c|}{$\begin{array}{l}\text { Basal insulin release } \\
(\mu \mathrm{U} / \mathrm{mg} / \mathbf{1 5} \mathrm{min})\end{array}$} & \multirow[t]{2}{*}{$\begin{array}{l}\text { Mean changes } \\
\text { in consecutive } \\
\text { incubations }\end{array}$} & \multicolumn{2}{|c|}{$\begin{array}{l}\text { Glucose mediated } \\
\text { insulin release } \\
\text { (\% change from basal) }\end{array}$} \\
\hline & mean & range & & mean & rang'e \\
\hline Hamster & $5.21^{\mathrm{a}}$ & 1.98 to 8.78 & $-11 \%$ & 197 & 98 to \\
\hline Mouse & $1.71^{\mathrm{b}}$ & 1.27 to 2.56 & $-37 \%$ & 66 & 30 to 91 \\
\hline Rabbit & $1.81^{\mathrm{c}}$ & 0.30 to 3.90 & $-39 \%$ & 650 & 200 to 1300 \\
\hline
\end{tabular}

a 40 individual experiments ( 850 pieces)

b 3 individual experiments ( 72 pieces)

c 26 individual experiments (725 pieces)

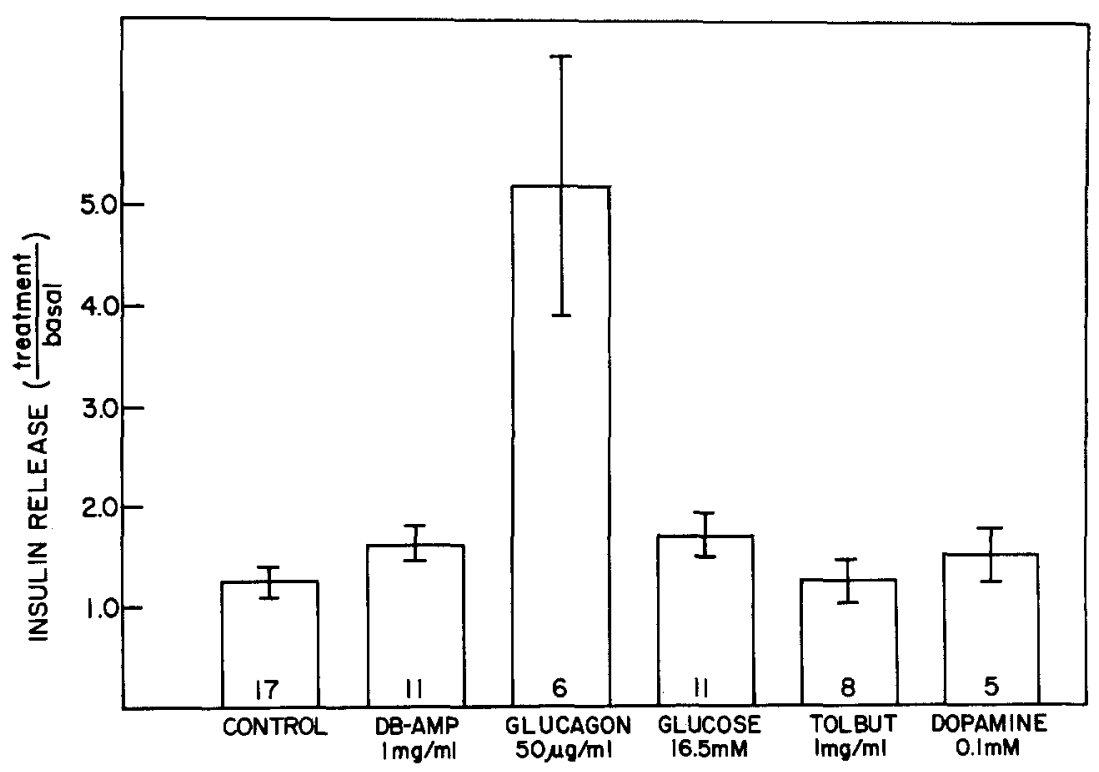

Fig. 2. The effect of various agents on in vitro insulin release from sand rat pancreas. For each individual animal, the results obtained for all pieces treated with the same agent ( 3 or 4 pieces) were averaged and used in the analysis as a single value. The numbers inside the bars indicate the number of animals whose pancreatic pieces were incubated with the specific treatment agent. The bars are the means and the brackets the S.E. derived from the averages for each animal. Control refers to the response of pancreatic pieces that were incubated with basal medium in the treatment incubation period as well. Glucose, tolbutamide, dibutyryl cyclic AMP (DB-AMP) and dopamine had no significant effect on insulin release as compared to the controls. Glucagon significantly stimulated insulin release $(p<0.001)$ 


\section{Discussion}

The diabetes mellitus-like syndrome of the sand rat is thought to result from alterations in the environment causing decompensation of a genetically transmitted defect. The nature of the genetic defect is unclear, and how environmental changes (increased caloric intake, stress, infection, etc.) induce glucose intolerance and ketosis is equally ambiguous. Administration of a high caloric diet to sand rats brought directly from Egypt led to a severe fulminating ketotic form of diabetes mellitus in a large percentage, while the remainder developed the more chronic nonketotic form of the disease $[3,4]$. It is of interest that as the sand rats have been bred in the laboratory, the diabetes mellitus-like syndrome has become much less severe. Successive generations of offspring have only rarely shown the acute ketotic form of the disease, and most animals now develop the milder form of the chronic non-ketotic illness. The population of sand rats used in this study were bred and kept in our colony for 1 to 2 years on various dietary programs. For the most part, they are very resistant to the development of the acute ketotic form of the disease and, if placed on a very high caloric diet, they will develop mild to moderate hyperglycemia and very markedly elevated plasma insulin levels. Why breeding under laboratory conditions has resulted in a change in the propensity of these animals to develop severe diabetes mellitus is unknown.

Table 1 indicates that some of the animals we studied were normal, while others had varying degrees of severity of mild, non-ketotic diabetes mellitus. The most significant parameter to indicate an aberrant metabolic state of the animals is the plasma insulin level. Only 3 of the animals were hyperglycemic at the time of the study, while 8 showed mild and 5 had moderate elevation of plasma insulin. Our studies of pancreatic insulin content and secretion therefore relate to normal or very mildly abnormal animals. In these types of sand rat, the pancreatic insulin content is quite high compared to either species in which spontaneous diabetes mellitus does not occur (golden hamsters $2.0 \pm 0.16 \mathrm{U} / \mathrm{g}[12]$; mice $3.78 \pm 0.45 \mathrm{U} / \mathrm{g}[13]$ or even in those in which it does occur. The only animal reported to have higher pancreatic insulin content is the spiny mouse [14]. While the pancreatic insulin content of our animals was not related to their previous endogenous insulin secretion (plasma insulin levels), the percent of the content released in a basal incubation was.

Basal insulin secretion in vitro from our sand rat pancreases is extremely high when compared to other species. Table 4 lists the characteristics of in vitro insulin secretion from pancreas pieces from golden hamsters, mice and rabbits $[12,13,15]$. It is unclear as to why in vitro insulin secretion in the basal state in normal sand rats should be 10 to 25 times higher than other species, even though the in vivo plasma insulin levels are comparable. Basal in vitro insulin secretion does increase in sand rats as the state of the animal changes, for as the plasma insulin level increases the basal in vitro release increases.

Insulin secretion from sand rat pancreas in vitro is not altered by agents that alter insulin secretion from the pancreas of other species. Neither glucose, tolbutamide, nor dibutyryl cyclic AMP is capable of increasing insulin secretion from sand rat pancreases while they do from the pancreas of most other species. Similarly, dopamine, which is a potent inhibitor of insulin secretion in other species [16] is without effect on insulin secretion from sand rat pancreas. The only agent which has any effect on insulin secretion from sand rat pancreas is glucagon. This series of studies indicates that pancreatic insulin secretion in the sand rat is under a series of unique controls. Similar studies need to be carried out with pancreases of other animals that develop spontaneous diabetes mellitus.

Our data are slightly different than other published information on the sand rat. Miki et al. [4] reported much lower pancreatic insulin content in their diabetic sand rats, but these were animals that had recently arrived from Egypt and were developing the acute, fulminating ketotic form of the disease. Malaisse et al. [17] studied in vitro insulin secretion from sand rats on various diets and reported variable results. The pancreases of animals fed a vegetable diet did not release insulin in response to glucose. Those from animals with severe diabetes likewise did not respond to glucose stimulation, while those from animals with diabetes of modest severity did. Pancreatic insulin content in his normal and mildly diabetic animals was high (3.6 to $10.0 \mathrm{U} / \mathrm{g}$ ) while that in his severely diabetic animals was low. Both his animal population and experimental techniques were different from ours, and it is difficult to compare the two sets of data.

The relationship between the unique control of insulin secretion in the sand rat and the development of the diabetic state is unknown. It seems likely that in his natural habitat the sand rat has little need for insulin to control his metabolic state. Indeed, we and others have shown that sand rat tissues are relatively resistant to insulin action $[5,6]$. It seems possible that the physiologic role of insulin in the sand rat might be other than controlling glucose and lipid metabolism, and thus, the control of its secretion might be responsive to factors involved in its physiologic action.

\section{References}

1. Aharonson, Z., Shani, J., Sulman, F.O.: Hypoglycemic effect of the salt bush (Atriplex halimus) A feeding source of the sand rat (Psammomys obesus). Diabetologia 5, 379-383 (1969)

2. Hackel, D.B., Mikat, E., Lebovitz, H.E., SchmidtNielsen, K. : Diabetes mellitus-like disease in sand rats (Psammomys obesus). Proc. VI Congress of the Inter- 
national Diabetes Federation. Excerpta Medica Int. Cong. Series 172, 800-805

3. Hackel, D.B., Frohman, L., Mikat, E., Lebovitz, H.E., Sehmidt-Nielsen, K., Kinney, T.D.: Effect of diet on the glucose tolerance and plasma insulin levels of the sand rat (Psammomys obesus). Diabetes 15, $105-114(1966)$

4. Miki, E., Like, A.A., Soeldner, J.S., Steinke, J., Cahill, G.F., Jr.: Acute ketotic-type diabetic syndrome in sand rats with special reference to the pancreas. Metabolism 15, 749-760 (1966)

5. Hackel, D.B., Mikat, E., Lebovitz, H. E., SchmidtNielsen, K., Horton, E.S., Kinney, T.D.: The sand rat (Psammomys obesus) as an experimental animal in studies of diabetes mellitus. Diabetologia 3, 130$134(1967)$

6. DeFronzo, R., Miki, E., Steinke, J.: Diabetic syndrome in sand rats. III Observations on adipose tissue and liver in the nondiabetic state. Diabetologia 3, $140-142(1967)$

7. Hackel, D.B., Lebovitz, H. E., Frohman, L.A., Mikat, E., Schmidt-Nielsen, K.: Effect of caloric restriction on the glucose tolerance and plasma insulin of the sand rat. Metabolism 16, $1133-1139$ (1967)

8. Scott, D.A., Fisher, A.M.: The insulin and zinc content of normal and diabetic pancreas. J. clin. Invest. 17, $725(1938)$

9. Morgan, C.R., Lazarow, A. : Immunoassay of insulin : Two antibody system. Diabetes 12, 115-126 (1963)

10. Saifer, A., Gerstenfeld, B.: The photometric microdetermination of blood glucose with glucose oxidase. J. Lab. clin. Med. 51, 448-460 (1958)
11. Snedecor, G. W., Cochran, W. G.: Statistical methods, 6th ed. Ames: Iowa State College Press 1967

12. Feldman, J.M., Lebovitz, H.E.: Role of pancreatic monoamines in the imparied insulin secretion of fasting. Endocrinology 92, $1469-1474$ (1973)

13. Feldman, J.M., Lebovitz, H.E.: Effect of fasting on insulin secretion and action in mice. Endocrinology 86, 313-321 (1970)

14. Stauffacher, W., Orci, L., Cameron, D.P., Burr, I.M., Renold, A.E.: Spontaneous hyperglycemia and/or obesity in laboratory rodents: An example of the possible usefulness of animal disease models with both genetic and environmental components. Recent Progr. Horm. Res. 27, 41-91 (1971)

15. Feldman, J.M., Quickel, K.E., Jr., Lebovitz, H.E.: Potentiation of insulin secretion in vitro by serotonin antagonists. Diabetes 21, $779-788$ (1972)

16. Quickel, K.E., Jr., Feldman, J.M., Lebovitz, H.E.: Inhibition of insulin secretion by serotonin and dopamine: Species variation. Endocrinology 89, $1295-1302$ (1971)

17. Malaisse, W.J., Like, A.A., Malaisse-Lagae, F., Gleason, R.E., Soeldner, J.S.: Insulin secretion in vitro by the pancreas of the sand rat (Psammomys obesus). Diabetes 17, 752-759 (1968)

Dr. Harold E. Lebovitz

Depts. of Medicine, Physiology and Pathology

Duke University School of Medicine

Durham, N.C.

USA 